
imidazoline $\mathrm{I}_{2}$ receptor ligand CR4056

PRECLINICAL RESEARCH

PHARMACODYNAMICS

Received

7 August 2014

Accepted

22 September 2014

Published

13 October 2014

Correspondence and requests for materials should be addressed to X.-H.H. (hexiaohua@ whu.edu.cn) or J.-X.L. (junxuli@buffalo.edu)

\section{in rats}

\author{
Yanyan Qiu' ${ }^{1,2}$, Xiao-Hua He², Yanan Zhang ${ }^{3}$ \& Jun-Xu Li'
}

'Department of Pharmacology and Toxicology, School of Medicine and Biomedical Sciences, University at Buffalo, Buffalo, NY, USA, ${ }^{2}$ Department of Physiology, School of Basic Medical Sciences, Wuhan University, Hubei, China, ${ }^{3}$ Research Triangle Institute, Research Triangle Park, NC, USA.

This study examined whether a novel imidazoline $I_{2}$ receptor ligand CR4056 could serve as a discriminative stimulus and whether it shares similar discriminative stimulus effects with other reported $I_{2}$ receptor ligands. Eight male Sprague-Dawley rats were trained to discriminate $10.0 \mathrm{mg} / \mathrm{kg} \mathrm{CR4056} \mathrm{(i.p.)} \mathrm{from} \mathrm{vehicle}$ in a two-lever food-reinforced drug discrimination procedure. Once rats acquired the discrimination, substitution and combination studies were conducted to elucidate the underlying receptor mechanisms. All rats acquired CR4056 discrimination after an average of 26 training sessions. Several $\mathrm{I}_{2}$ receptor ligands (phenyzoline, tracizoline, RS45041, and idazoxan, 3.2-75 mg/kg, i.p.) all occasioned $>80 \%$ CR4056-associated lever responding. Other drugs that occasioned partial or no CR4056-associated lever responding included methamphetamine, ketamine, the endogenous imidazoline ligand agmatine, the monoamine oxidase (MAO) inhibitor harmane, the $\alpha_{2}$-adrenoceptor agonist clonidine, the $\mu$-opioid receptor agonists morphine and methadone, and the selective $I_{2}$ receptor ligands BU224 and 2-BFI. The $\alpha_{1}$ adrenoceptor antagonist WB4101, $\alpha_{2}$ adrenoceptor antagonist yohimbine and $\mu$-opioid receptor antagonist naltrexone failed to alter the stimulus effects of CR4056. Together, these results show that CR4056 can serve as a discriminative stimulus in rats, which demonstrates high pharmacological specificity and appears to be mediated by imidazoline $\mathrm{I}_{2}$ receptors.

midazoline receptors represent a group of heterogeneous receptors (e.g., $\mathrm{I}_{1}, \mathrm{I}_{2}$ and $\mathrm{I}_{3}$ subtypes) that involve diverse physiological and/or pharmacological functions ${ }^{1,2}$. In particular, $\mathrm{I}_{2}$ receptors have recently been increasingly recognized as a potential target for the development of novel analgesics ${ }^{3-7}$.

Until now, the molecular identity and downstream signaling transduction mechanism of $\mathrm{I}_{2}$ receptors remain unclear and the understanding of $\mathrm{I}_{2}$ receptors relies primarily on pharmacological tools. In the past two decades, several selective $I_{2}$ receptor ligands with varying potency and affinity have been described ${ }^{5,8-10}$. However, little is known of the comparative pharmacology of these ligands as few studies have examined the effects of these $\mathrm{I}_{2}$ receptor ligands using functional assays. We previously showed that a group of seven putative $\mathrm{I}_{2}$ receptor ligands all exert hypothermic activity in rats which appears to be mediated through $\mathrm{I}_{2}$ receptors ${ }^{11}$. Further comparative pharmacology study of the reported $\mathrm{I}_{2}$ receptor ligands remains important because without the knowledge of $\mathrm{I}_{2}$ receptor identity and with the fact that essentially all compounds bind to more than one receptor, future studies using selected $I_{2}$ receptor ligands to understand $I_{2}$ receptor pharmacology depend on how well we know the similarities and differences of these valuable ligands as research tools.

Drug discrimination is a widely used behavioral pharmacology procedure to study receptor mechanisms underlying the effects of drugs from various pharmacological classes primarily due to its high pharmacological specificity. Of the reported $\mathrm{I}_{2}$ receptor ligands, only 2-BFI has been studied as a discriminative stimulus. It was found that rats can recognize 2-BFI as a discriminative stimulus, and that the effect is pharmacologically specific and seems to be associated with irreversible inhibition of monoamine oxidase A (MAO-A) ${ }^{12-14}$.

CR4056 is a newly described highly selective $\mathrm{I}_{2}$ receptor ligand ${ }^{5}$. In a receptor characterization study including 35 common receptors, enzymes and ion channels, CR4056 shows high affinity at $\mathrm{I}_{2}$ receptors and MAO-A but negligible binding activity at all other sites, demonstrating its high receptor selectivity ${ }^{5}$. In preclinical studies, CR4056 demonstrates potent antinociceptive activity in rodent models of persistent inflammatory and neuropathic pain ${ }^{3,5,7}$. CR4056 also produces hypothermia in rats to a degree that is similar with other $\mathrm{I}_{2}$ receptor ligands ${ }^{11}$. Given the well-characterized high $\mathrm{I}_{2}$ receptor selectivity, this offers an opportunity to use drug dis- 

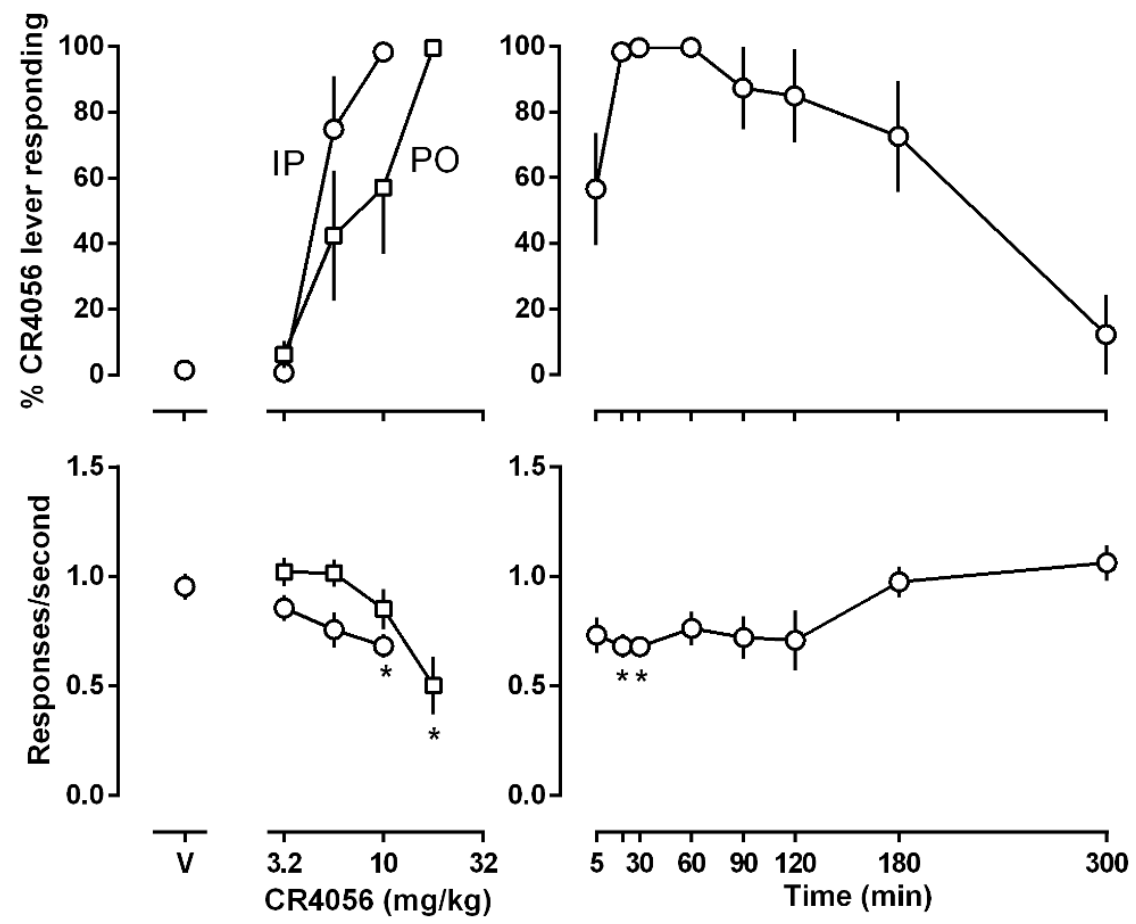

Figure 1 Effects of CR4056 in rats trained to discriminate between $10 \mathrm{mg} / \mathrm{kg}$ CR4056 (i.p) and vehicle using a two-lever food-reinforced procedure. The mean $( \pm 1$ SEM) percentage of responses on the CR4056-appropriate lever (top panels) and the mean ( \pm 1 SEM) rate of responding (bottom panels) are plotted as a function of dose in the left panels and as a function of time after i.p. administration of $10 \mathrm{mg} / \mathrm{kg}$ CR 4056 in the right panels. Points above "V" indicate vehicle. Each point represents the average ( \pm S.E.M.) of eight rats. Asterisks indicate mean rate of responding that were significantly different from control (95\% CLs did not overlap).

crimination procedure to characterize the discriminative stimulus effects of CR4056 and compare it with other purported $\mathrm{I}_{2}$ receptor ligands, which will also assist in understanding the functionality of $\mathrm{I}_{2}$ receptors.

\section{Results}

At the training dose of $10 \mathrm{mg} / \mathrm{kg}$ (i.p.), all 8 subjects acquired CR4056 discrimination after an average of 26 (range $=11-52$ ) training sessions, including the sessions used for the calculation of criteria performance.

CR4056 dose- and time-dependently produced discriminative stimulus effects, with the highest dose slightly but significantly reducing the rate of responding (Fig. 1). When tested with different doses, CR4056 increased responding on the CR4056-associated lever in a dose-dependent manner, ranging from $1 \%$ after vehicle injection to a maximum of $98 \%$ after injecting with the training dose of $10 \mathrm{mg} / \mathrm{kg}$ CR4056 $\left[\mathrm{ED}_{50}(95 \% \mathrm{CLs})=5.0(4.0,5.9) \mathrm{mg} / \mathrm{kg}\right]$ (upper left panel, open circles), with the dose of $10 \mathrm{mg} / \mathrm{kg}$ slightly but significantly reducing response rate (lower left panel, open circles). Oral administration of CR4056 only slightly reduced its potency for producing CR4056-appropriate lever responding $\left[\mathrm{ED}_{50}(95 \% \mathrm{CLs})=9.2(4.7\right.$, $12.5) \mathrm{mg} / \mathrm{kg}$ ] (upper left panel, open squares) and CR4056 significantly decreased rate of responding at the highest oral dose tested $(17.8 \mathrm{mg} / \mathrm{kg})$ (lower left panel, open squares). In tests to examine the duration of action of the training dose of CR4056 (i.e., $10 \mathrm{mg} / \mathrm{kg}$, i.p.), drug was administered with varying pretreatment times. It was found that the discriminative stimulus effects of CR4056 were apparent after 5 min pretreatment, reached the maximal effect after 30 min pretreatment and decreased to $12 \% 5$ hours later (top right panel), with response rate slightly but significantly decreased at 20 and 30 min time points.

Four reported imidazoline $\mathrm{I}_{2}$ receptor ligands phenyzoline, RS45041, idazoxan and tracizoline produced greater than 80\% CR4056-like discriminative stimulus effects and at the highest doses that produced maximal stimulus effects they also significantly reduced response rates (Fig. 2). $\mathrm{ED}_{50}$ (95\% CLs) values of these drugs for substituting CR4056 were: phenyzoline $38.7(23.1,50.2) \mathrm{mg} / \mathrm{kg}$, RS45041 11.2 $(4.8,15.2) \mathrm{mg} / \mathrm{kg}$, idazoxan $9.6(4.8,14.5) \mathrm{mg} / \mathrm{kg}$, and tracizoline $51.3(40.9,61.6) \mathrm{mg} / \mathrm{kg}$. The commonly used $\mathrm{I}_{2}$ receptor ligand $2-$ BFI failed to produce full substitution to CR4056 discrimination, increasing CR4056-appropriate responding to at most 75\% at a dose $(10 \mathrm{mg} / \mathrm{kg})$ that significantly reduced rate of responding (Fig. 2). Another commonly used $\mathrm{I}_{2}$ receptor ligand BU224 failed to produce greater than 20\% CR4056-appropriate responding up to a dose $(17.8 \mathrm{mg} / \mathrm{kg}$ ) that markedly suppressed operant responding (Fig. 2).

Drugs that have no known $\mathrm{I}_{2}$ receptor binding activities generally produced partial or no CR4056-like discriminative stimulus effects. The opioids morphine and methadone increased CR4056-appropriate responding to at most $67 \%$ (morphine) and 56\% (methadone) (open triangles, upper panels, Fig. 3) when tested up to doses that significantly reduced rate of responding (lower panels, Fig. 3). The NMDA receptor antagonist ketamine produced a maximum of $13 \%$ CR4056-appropriate responding up to a dose $(17.8 \mathrm{mg} / \mathrm{kg})$ that eliminated operant responding (open diamonds, Fig. 3). The monoamine releaser methamphetamine produced a maximum of $38 \%$ CR4056-associated lever-responding up to a dose $(5.6 \mathrm{mg} / \mathrm{kg})$ that eliminated operant responding (filled circles, Fig. 3). The putative endogenous imidazoline receptor ligand agmatine produced a maximum of 50\% CR4056-associated responding up to a dose $(100 \mathrm{mg} /$ $\mathrm{kg}$ ) that significantly decreased rate of responding (open circles, Fig. 3). A $\beta$-carboline harmane produced a maximum of $33 \%$ CR4056-associated responding up to a dose $(10 \mathrm{mg} / \mathrm{kg})$ that significantly suppressed rate of responding (open squares, Fig. 3). The $\alpha_{2}$ adrenoceptor agonist clonidine produced a maximum of $47 \%$ CR4056-appropriate responding up to a dose $(0.1 \mathrm{mg} / \mathrm{kg})$ that significantly reduced response rate (filled diamonds, Fig. 3 ).

The opioid receptor antagonist naltrexone and the $\alpha_{2}$ adrenoceptor antagonist yohimbine failed to attenuate the discriminative 

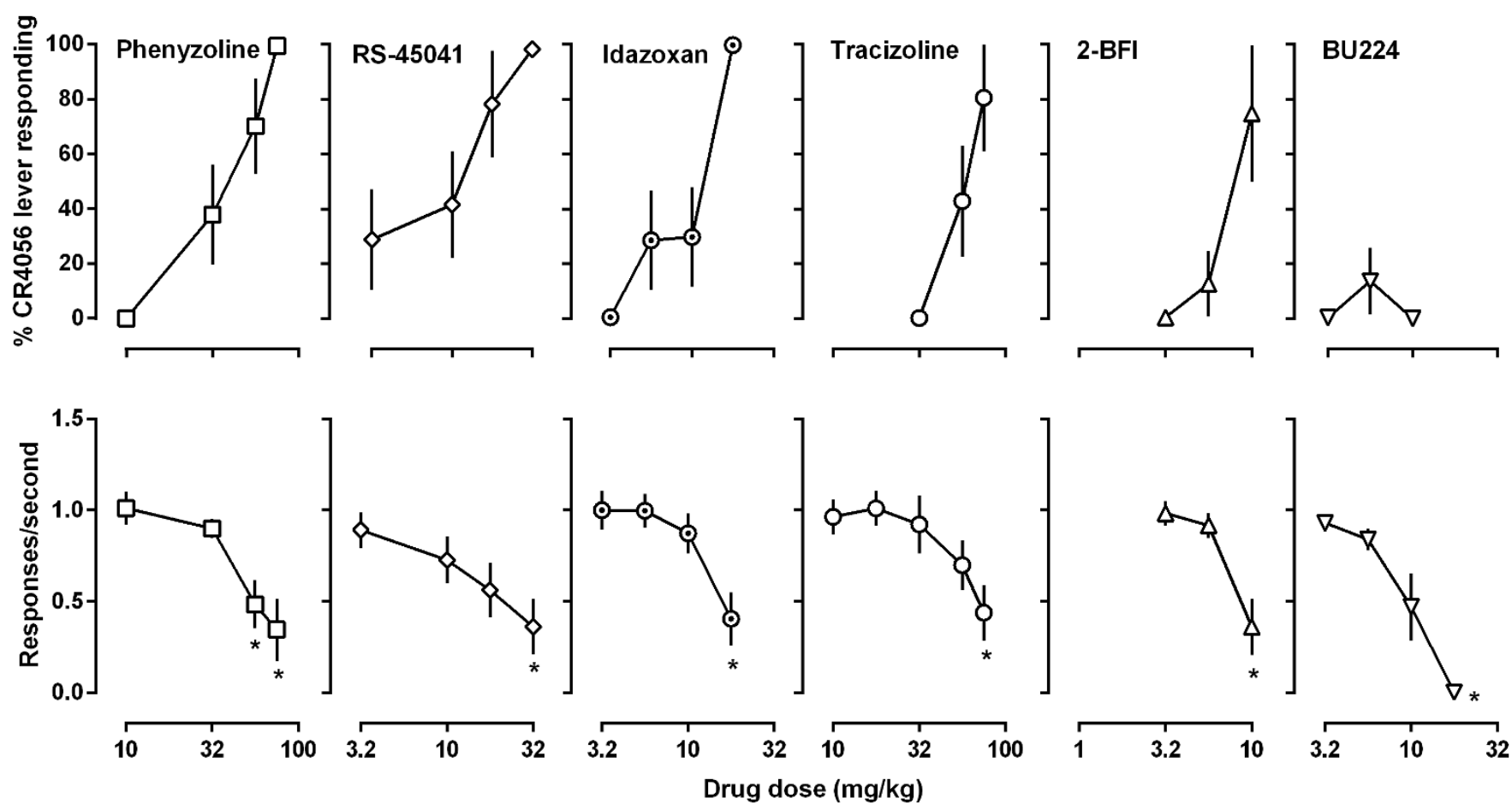

Figure 2 Effects of phenyzoline, RS45041, idazoxan, tracizoline, 2-BFI and BU224 in rats trained to discriminate between $10 \mathrm{mg} / \mathrm{kg} \mathrm{CR4056} \mathrm{(i.p)} \mathrm{and}$ vehicle using a two-lever food-reinforced procedure. See Figure 1 for other details.

stimulus effects of CR4056 (open diamonds and open squares, respectively, Fig. 4). The dose ratios (95\% CLs) of CR4056 in the absence and presence of $0.32 \mathrm{mg} / \mathrm{kg}$ naltrexone or $2 \mathrm{mg} / \mathrm{kg}$ yohimbine were $2.7(0.7,4.8)$ and $1.1(0.8,1.3)$, respectively. Because the $95 \%$ CLs of the dose ratios included 1, the potency changes of CR4056 in the presence of naltrexone or yohimbine were considered insignificant. Because the commonly used $\mathrm{I}_{2}$ receptor ligand BU224 failed to produce significant CR4056-like discriminative stimulus effects, it was studied in combination with CR4056. Pretreatment with $5.6 \mathrm{mg} / \mathrm{kg}$ BU224 significantly decreased the potency of CR4056 (open upper triangles, Fig. 4). The dose ratio (95\% CLs) of CR4056 in the absence and presence of $5.6 \mathrm{mg} / \mathrm{kg}$ BU224 was 4.0
$(1.9,6.1)$, representing a 4 -fold leftward shift of the CR4056 dose response curve.

The $\alpha_{1}$ adrenoceptor antagonist WB4101 failed to attenuate the discriminative stimulus effects of the training dose of CR4056 (i.e., $10 \mathrm{mg} / \mathrm{kg}$ ) up to a dose that markedly reduced the operant responding (Fig. 5).

\section{Discussion}

This study firstly demonstrated that rats can be trained to discriminate the novel imidazoline $\mathrm{I}_{2}$ receptor ligand CR4056 from vehicle. All the eight animals met the test criteria after an average of 26 (range: 11-52) training sessions, suggesting that CR4056 is at least
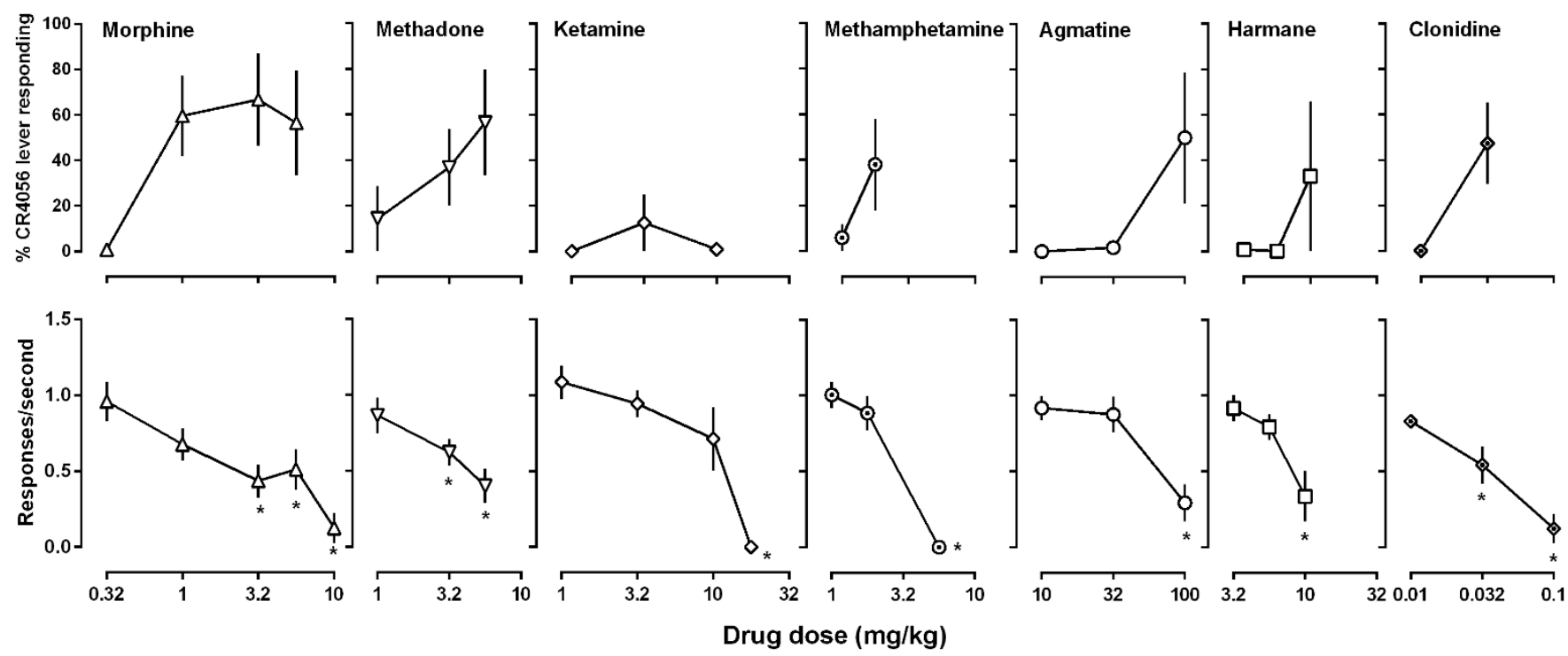

Figure 3 Effects of morphine, methadone, ketamine, methamphetamine, agmatine, harmane and clonidine in rats trained to discriminate between $10 \mathrm{mg} / \mathrm{kg} \mathrm{CR} 4056$ (i.p) and vehicle using a two-lever food-reinforced procedure. See Figure 1 for other details. 

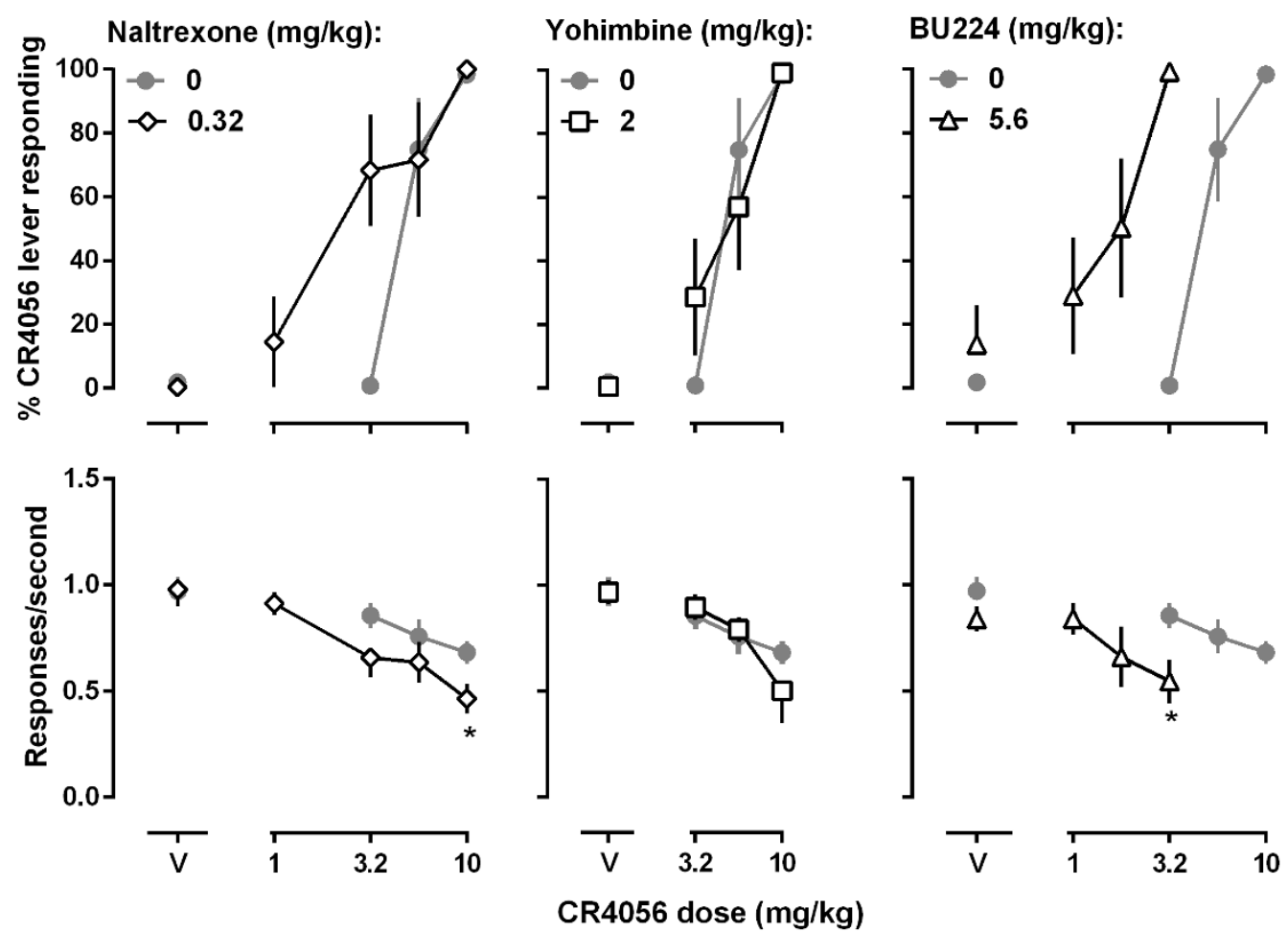

Figure 4 Effects of naltrexone, yohimbine and BU224 on the discriminative stimulus effects of CR4056 in rats trained to discriminate between $10 \mathrm{mg} /$ kg CR4056 (i.p) and vehicle using a two-lever food-reinforced procedure. Pretreatment drugs were administered 10 min prior to CR4056. See Figure 1 for other details.

as discriminable as 2-BFI (an average of $57 \pm 9$ training sessions) ${ }^{13}$. In addition, the discriminative stimulus effects of CR4056 is pharmacologically highly specific such that only drugs that have known binding affinities at $\mathrm{I}_{2}$ receptors (except BU224) produced CR4056-
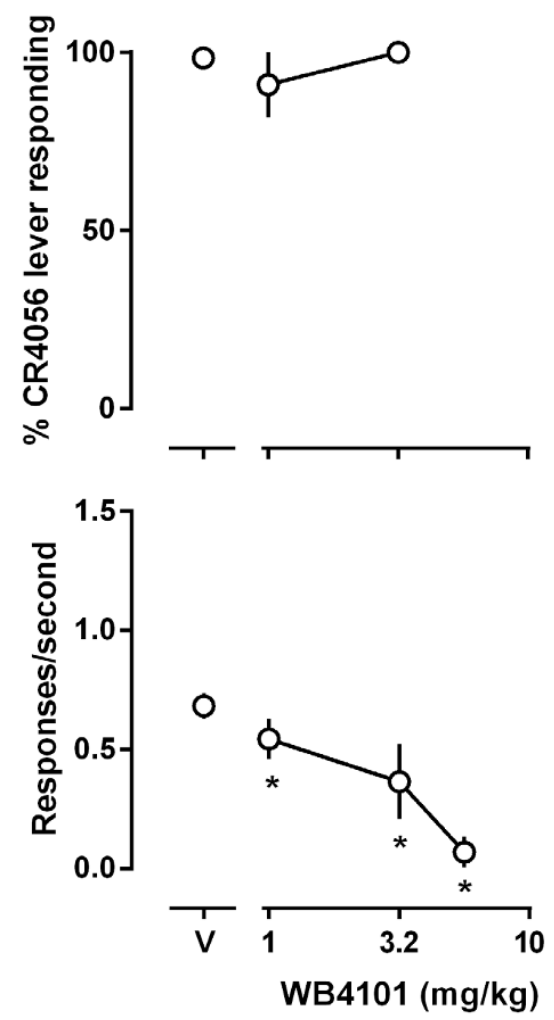

Figure 5 | Effects of WB4101 on the discriminative stimulus effects of the training dose of CR4056 $(10 \mathrm{mg} / \mathrm{kg})$ in rats. See Figure 1 for other details. like discriminative stimulus effects. Findings from antagonism studies suggest that opioid receptors and $\alpha_{1} / \alpha_{2}$ adrenoceptors do not play a prominent role in the discriminative stimulus effects of CR4056.

CR4056 is a recently characterized imidazoline $\mathrm{I}_{2}$ receptor ligand that demonstrates high selectivity at $\mathrm{I}_{2}$ receptors over a panel of more than 35 other common receptors, enzymes and binding sites ${ }^{5}$. CR4056 can readily cross the blood brain barrier and demonstrates strong antinociceptive activity in several rodent models of persistent inflammatory and neuropathic pain ${ }^{3,5,7}$. In the current study, the discriminative stimulus effects of the training dose of CR4056 lasted about 5 hours, which is consistent with the duration of its antinociceptive effects (around 6 hours at an oral dose of $20 \mathrm{mg} / \mathrm{kg}$ ) ${ }^{5}$. Phenyzoline, RS45041 and tracizoline all have high affinity and selectivity at $I_{2}$ receptors ${ }^{9,15,16}$ and they all fully substituted for the discriminative stimulus effects of CR4056. Importantly, drugs that do not bind to $\mathrm{I}_{2}$ receptors do not mimic the discriminative stimulus effects of CR4056. For example, ketamine and methamphetamine did not occasion significant CR4056-like discriminative cueing effects. These results suggest that the discriminative stimulus effects of CR4056 are likely mediated through $\mathrm{I}_{2}$ receptors. Both morphine and methadone produced dose-dependent and partial substitution for CR4056 and the effects were antagonized by naltrexone (data not shown), suggesting that $\mu$ opioid receptors might be involved in the discriminative stimulus effects of CR4056. However, subsequent antagonist studies with naltrexone found that naltrexone did not alter the effects of CR4056, which suggests that although a small secondary role cannot be ruled out, it is unlikely that interactions of CR4056 with $\mu$ opioid receptors play a major role in its discriminative stimulus effects.

Idazoxan is traditionally used to identify and characterize $\mathrm{I}_{2}$ receptors $^{17}$ and has been shown to block the antinociceptive effects of CR4056, 2-BFI and phenyzoline ${ }^{3,5,16}$. In rats discriminating 2-BFI, idazoxan produces full 2-BFI-like discriminative stimulus effects ${ }^{14}$. In the current study, idazoxan produced full CR4056-like discriminative stimulus effects. It is possible that idazoxan has lower efficacy 
at $\mathrm{I}_{2}$ receptors than 2-BFI and CR4056 and functions as a partial agonist. Thus, in assays that have higher efficacy demand (e.g., antinociception) idazoxan serves as an antagonist while in assays that have lower efficacy demand (e.g., drug discrimination) idazoxan is fully effective. However, there are cases that idazoxan does not enhance or block the behavioral effects of 2-BFI and BU224 $4^{18}$.

2 -BFI and BU224 are two most widely studied $\mathrm{I}_{2}$ receptor ligands. In rats discriminating 2-BFI, BU224 fully substitutes for $2-\mathrm{BFI}^{13}$. All three compounds (2-BFI, BU224 and CR4056) produce hypothermia in rats ${ }^{11}$ and produce antinociceptive effects through their actions on $\mathrm{I}_{2}$ receptors ${ }^{3,5,19}$. Thus, it is expected that these compounds share similar pharmacological mechanisms (i.e., $\mathrm{I}_{2}$ receptors). However, the current data suggest that there are important differences among these compounds. First, 2-BFI only partially substituted for while BU224 did not substitute for CR4056. Second, the stimulus effects of 2-BFI is significantly antagonized by the $\alpha_{1}$ adrenoceptor antagonist WB4101 ${ }^{12}$ but WB4101 did not block the discriminative stimulus effects of CR4056 (Fig. 5). Third, the MAO-A inhibitor harmane fully substitutes for 2 -BFI in rats discriminating $2-\mathrm{BFI}^{13}$ but it did not substitute for CR4056 (Fig. 3). There is evidence that BU224 has lower efficacy than 2-BFI because it blocks the behavioral effects of 2-BFI under certain conditions ${ }^{20,21}$ and is sometimes used as an $\mathrm{I}_{2}$ receptor antagonist ${ }^{22,23}$. However, the lack of substitution of BU224 for CR4056 in the current study does not seem to be due to its limited efficacy at $\mathrm{I}_{2}$ receptors, because if this were the case then it would be expected that BU224 should be able to antagonize the effects of CR4056. In contrast, BU224 markedly enhanced the discriminative stimulus effects of CR4056. Both 2-BFI and CR4056 are highly selective $\mathrm{I}_{2}$ receptor ligands and counter selectivity binding studies fail to identify any receptor that these compounds bind with high affinity other than $\mathrm{I}_{2}$ receptors ${ }^{5,24}$. One parsimonious explanation is that the pharmacological mechanisms of these compounds are overlapping but have important (yet unknown) differences.

Imidazoline $\mathrm{I}_{2}$ receptors as identified by idazoxan or 2-BFI binding are highly heterogeneous and include several proteins ${ }^{17,25,26}$, including $\mathrm{a} \sim 45 \mathrm{kDa}$ protein that was recently identified as brain creatine kinase ${ }^{26}$. However, little is known of the molecular identity and functional activity of these heterogeneous proteins. In most functional studies, $\mathrm{I}_{2}$ receptors are treated as one homogenous receptor for the sake of convenience. However, emerging functional data including the current study increasingly suggest that these proteins that 2-BFI and idazoxan bind to may have different functionalities, although it is too early to link specific functions with particular proteins. For example, it is plausible that CR4056, 2-BFI and BU224 binding profiles on the idazoxan-recognized proteins are overlapping but have important differences. It is possible that the protein(s) underlying the antinociceptive effects of these $\mathrm{I}_{2}$ receptor ligands is different from that underlying the discriminative stimulus effects or hypothermic effects ${ }^{11}$. Thus, BU224 may only bind to one component of the CR4056 binding sites which may not be sufficient to produce CR4056-like discriminative stimulus effects but adequate to enhance the effects of CR4056 by increasing the activity on the same component that CR4056 also binds to. These speculations need to be tested in future studies that utilize multiple $\mathrm{I}_{2}$ receptor ligands and different functional assays to categorize the potential effects of the different $\mathrm{I}_{2}$ receptor components.

In summary, this study for the first time demonstrates that CR4056 can serve as a discriminative stimulus in rats and the effects are pharmacologically specific that seem to be mediated through imidazoline $\mathrm{I}_{2}$ receptors but not through opioid or $\alpha_{1} / \alpha_{2}$ adrenoceptors. The discriminative stimulus effects of CR4056 have important differences from those of 2-BFI, which is reminiscent of the biochemical heterogeneity of $\mathrm{I}_{2}$ receptors and may indicate functional diversity of $\mathrm{I}_{2}$ receptors. Drug discrimination is a valuable tool to investigate the in vivo pharmacological properties of putative $\mathrm{I}_{2}$ receptor ligands and provides another dimension toward fuller understanding of $\mathrm{I}_{2}$ receptor ligands and $\mathrm{I}_{2}$ receptor functionality.

\section{Methods}

Subjects. Eight adult male Sprague-Dawley rats (Harlan, Indianapolis, IN) were housed individually on a $12 / 12$-h cycle (behavioral experiments were conducted during the light period) with free access to water and restricted access to food. The body weights of the rats were maintained at $85 \%$ of their free-feeding body weights by adjusting the amount of standard rodent chow that was provided in the home cages after daily sessions. All animal maintenance and experimental protocols were approved by the Institutional Animal Care and Use Committee, University at Buffalo, and conducted in accordance to the 2011 Guide for the Care and Use of Laboratory Animals (Institute of Laboratory Animal Resources on Life Sciences, National Research Council, National Academy of Sciences).

Apparatus. Experiments were conducted in commercially available chambers within sound-attenuating, ventilated enclosures (Coulbourn Instruments Inc., Allentown, PA, USA). Each chamber contained a working area of $30.5 \mathrm{~cm}$ by $24.5 \mathrm{~cm}$ by $21.0 \mathrm{~cm}$, a grid floor, and a $45 \mathrm{mg}$ pellet dispenser with a pellet receptacle that was centered between responses levers, above which were stimulus lights. A $28 \mathrm{~V}$ house light was mounted on the rear aluminum wall of the chamber. Chambers were connected to a computer running Graphic State 3.03 software and an interface (Coulbourn Instruments Inc.) to control experimental events and record data.

Drug Discrimination Procedure. Rats were trained to discriminate $10.0 \mathrm{mg} / \mathrm{kg}$ CR4056 (i.p.) from vehicle while responding under a fixed ratio (FR) 10 schedule of food presentation. The experimental procedure described by Li was followed ${ }^{27}$.

Daily sessions began with a 10 -min timeout period, during which the chamber was dark and lever presses had no programmed consequence, followed by a response period, during which stimulus lights above both levers were illuminated and an FR 10 schedule of food presentation was active. Either saline or CR4056 was injected intraperitoneally $10 \mathrm{~min}$ before the start of daily sessions. When rats received saline, only responding on the saline-associated lever resulted in food delivery (45 mg; BioServ Inc., Frenchtown, New Jersey, USA), and when they received CR4056 only responding on the other (drug-associated) lever resulted in food delivery. Sessions were conducted 7 days per week according to a double alternation schedule (e.g., saline, saline, drug, drug).

Rats had to satisfy the following criteria for five consecutive or six of seven consecutive sessions: at least $90 \%$ of the total responses on the correct lever and fewer than ten responses on the incorrect lever before completion of the FR on the correct lever. Thereafter, tests were conducted every 3rd day provided that the testing criteria were satisfied during intervening training sessions. If rats failed to satisfy these criteria, training continued until the criteria were satisfied for two consecutive sessions.

Test sessions were identical to training sessions with the exception that ten consecutive responses on either lever resulted in the delivery of food and different doses of CR4056 and other drugs were administered. In the study that examined the effects of oral administration of CR4056, the drug was administered via gavage 30 min prior to the start of the sessions. In combination studies that involved two drug injections, the pretreatment drug was always administered $10 \mathrm{~min}$ prior to the second drug injection. In general, drugs were studied up to doses that occasioned at least $80 \%$ responding on the drug-associated lever or to doses that decreased the rate of responding significantly.

Data Analyses. The mean percentage of responses on CR4056-associated lever $( \pm 1$ S.E.M.) was plotted as a function of dose. If the response rate of an animal was less than $20 \%$ of the vehicle control rate, discrimination data from that test were not included for further analysis. Linear regression was used to analyze the dose response curves that attained at least $80 \%$ CR4056-appropriate responding and to estimate the dose required to produce $50 \%$ responding on the CR4056-appropriate lever $\left[\mathrm{ED}_{50} \pm\right.$ $95 \%$ confidence limits (CLs)]. In drug combination studies that determined complete dose response curves, dose ratios $\left(\mathrm{ED}_{50}\right.$ values of CR4056 before drug treatment divided by those after drug treatment) were calculated to estimate the magnitude of shift in the CR4056 dose response curve produced by other drugs. When the 95\% CLs of the mean dose ratio did not encompass 1, the CR4056 dose-response curve was considered to be shifted significantly leftward. Response rates were expressed as the average ( \pm 1 S.E.M.) number of responses per second on both levers. If the $95 \%$ CLs of the response rates after drug treatment did not overlap with those after vehicle treatment, it was considered that the drug significantly altered the response rate.

Drugs. CR4056, 2-BFI hydrochloride, BU224 hydrochloride, phenyzoline oxalate and tracizoline oxalate were synthesized according to standard procedures at the Research Triangle Institute and fully characterized by NMR and elemental analysis. RS45041 was kindly provided by National Institute of Mental Health's Chemical Synthesis and Drug Supply program (Bethesda, MD, USA). Idazoxan hydrochloride, agmatine hydrochloride, clonidine hydrochloride, yohimbine hydrochloride, naltrexone hydrochloride, harmane hydrochloride and WB4101 hydrochloride were purchased from Sigma-Aldrich (St. Louis, MO, USA). Ketamine hydrochloride was purchased from Patterson Veterinary (Devens, MA, USA). Morphine sulfate, methadone hydrochloride and methamphetamine hydrochloride were provided by Research Technology Branch, National Institute on Drug Abuse, National Institutes of Health (Rockville, MD, USA). All drugs were dissolved in $0.9 \%$ physiological saline 
except CR4056 which was dissolved in 20\% DMSO with saline and a drop of hydrochloric acid.

1. Parini, A., Moudanos, C. G., Pizzinat, N. \& Lanier, S. M. The elusive family of imidazoline binding sites. Trends Pharmacol. Sci. 17, 13-16 (1996).

2. Eglen, R. M. et al. 'Seeing through a glass darkly': casting light on imidazoline 'I' sites. Trends Pharmacol Sci 19, 381-390 (1998).

3. Li, J. X., Thorn, D. A., Qiu, Y., Peng, B. W. \& Zhang, Y. Antihyperalgesic effects of imidazoline $\mathrm{I}(2)$ receptor ligands in rat models of inflammatory and neuropathic pain. Br J Pharmacol 171, 1580-1590 (2014).

4. Li, J. X. \& Zhang, Y. Imidazoline I2 receptors: target for new analgesics? Eur J Pharmacol 658, 49-56 (2011).

5. Ferrari, F. et al. Analgesic efficacy of CR4056, a novel imidazoline-2 receptor ligand, in rat models of inflammatory and neuropathic pain. J. Pain Research 4 , 111-125 (2011).

6. Lanza, M., Ferrari, F., Menghetti, I., Tremolada, D. \& Caselli, G. Modulation of imidazoline I2 binding sites by CR4056 relieves postoperative hyperalgesia in male and female rats. Br. J. Pharmacol. 171, 3693-3701 (2014).

7. Meregalli, C. et al. CR4056, a new analgesic I2 ligand, is highly effective against bortezomib-induced painful neuropathy in rats. J. Pain Research 5, 151-167 (2012).

8. Hudson, A. L. et al. Novel selective compounds for the investigation of imidazoline receptors. Ann. New York Acad. Sci. 881, 81-91 (1999).

9. Brown, C. M. et al. RS-45041-190: a selective, high-affinity ligand for I2 imidazoline receptors. Br. J. Pharmacol. 116, 1737-1744 (1995).

10. Gentili, F. et al. Novel ligands rationally designed for characterizing I2imidazoline binding sites nature and functions. J. Med. Chem. 51, 5130-5134 (2008).

11. Thorn, D. A., An, X. F., Zhang, Y., Pigini, M. \& Li, J. X. Characterization of the hypothermic effects of imidazoline I(2) receptor agonists in rats. Br. J. Pharmacol. 166, 1936-1945 (2012).

12. MacInnes, N. \& Handley, S. L. Potential serotonergic and noradrenergic involvement in the discriminative stimulus effects of the selective imidazoline I2site ligand 2-BFI. Pharmacol. Biochem. Behav. 75, 427-433 (2003).

13. MacInnes, N. \& Handley, S. L. Characterization of the discriminable stimulus produced by 2-BFI: effects of imidazoline I(2)-site ligands, MAOIs, betacarbolines, agmatine and ibogaine. Br. J. Pharmacol. 135, 1227-1234 (2002).

14. Jordan, S., Jackson, H. C., Nutt, D. J. \& Handley, S. L. Discriminative stimulus produced by the imidazoline I2 site ligand, 2 -BFI. J. Psychopharmacology 10, 273-278 (1996).

15. Pigini, M. et al. Imidazoline receptors: qualitative structure-activity relationships and discovery of tracizoline and benazoline. Two ligands with high affinity and unprecedented selectivity. Bioorg. Med. Chem. 5, 833-841 (1997).

16. Gentili, F. et al. Involvement of I2-imidazoline binding sites in positive and negative morphine analgesia modulatory effects. Eur. J. Pharmacol. 553, 73-81 (2006).

17. Regunathan, S. \& Reis, D. J. Imidazoline receptors and their endogenous ligands. Ann. Review Pharmacol. Toxicol. 36, 511-544 (1996).

18. Min, J. W., Peng, B. W., He, X., Zhang, Y. \& Li, J. X. Gender difference in epileptogenic effects of 2-BFI and BU224 in mice. Eur. J. Pharmacol. 718, 81-86 (2013).

19. Li, J. X., Zhang, Y. \& Winter, J. C. Morphine-induced antinociception in the rat: supra-additive interactions with imidazoline I(2) receptor ligands. Eur. J. Pharmacol. 669, 59-65 (2011).
20. Thorn, D. A., Zhang, Y., Peng, B. W., Winter, J. C. \& Li, J. X. Effects of imidazoline I(2) receptor ligands on morphine- and tramadol-induced antinociception in rats. Eur. J. Pharmacol. 670, 435-440 (2011).

21. Sanchez-Blazquez, P., Boronat, M. A., Olmos, G., Garcia-Sevilla, J. A. \& Garzon, J. Activation of I(2)-imidazoline receptors enhances supraspinal morphine analgesia in mice: a model to detect agonist and antagonist activities at these receptors. Br. J. Pharmacol. 130, 146-152 (2000).

22. Chen, M. F. et al. Characterization of imidazoline receptors in blood vessels for the development of antihypertensive agents. BioMed Res. Intl. 2014, 182846 (2014).

23. Yang, T. T. et al. Mediation of AMP kinase in the increase of glucose uptake in L6 cells induced by activation of imidazoline I-2 receptors. Hormone Metab. Res. 45, 359-363 (2013).

24. Nutt, D. J. et al. Functional studies of specific imidazoline-2 receptor ligands. Ann. New York Acad. Sci. 763, 125-139 (1995).

25. Escriba, P. V., Ozaita, A. \& Garcia-Sevilla, J. A. Pharmacologic characterization of imidazoline receptor proteins identified by immunologic techniques and other methods. Ann. New York Acad. Sci. 881, 8-25 (1999).

26. Kimura, A. et al. Identification of an imidazoline binding protein: creatine kinase and an imidazoline-2 binding site. Brain Res. 1279, 21-28 (2009).

27. Li, J. X., Thorn, D. A. \& Jin, C. The GPR88 receptor agonist 2-PCCA does not alter the behavioral effects of methamphetamine in rats. Eur. J. Pharmacol. 698 272-277 (2013)

\section{Acknowledgments}

This work was supported by the National Institute on Drug Abuse of the National Institutes of Health (Awards no. R01DA034806 and R21DA033426). The content is solely the responsibility of the authors and does not necessarily represent the official views of the National Institutes of Health.

\section{Author contributions}

Y.Q. and J.L. participated in research design; Y.Q. conducted the experiments; Y.Z. provided test compounds; Y.Q. and J.L. conducted data analyses; Y.Q., X.H., Y.Z. and J.L. prepared and approved the final version of the manuscript.

\section{Additional information}

Competing financial interests: The authors declare no competing financial interests.

How to cite this article: Qiu, Y., He, X.-H., Zhang, Y. \& Li, J.-X. Discriminative stimulus effects of the novel imidazoline $\mathrm{I}_{2}$ receptor ligand CR4056 in rats. Sci. Rep. 4, 6605; DOI:10.1038/srep06605 (2014)

This work is licensed under a Creative Commons Attribution-NonCommercialShareAlike 4.0 International License. The images or other third party material in this article are included in the article's Creative Commons license, unless indicated otherwise in the credit line; if the material is not included under the Creative Commons license, users will need to obtain permission from the license holder in order to reproduce the material. To view a copy of this license, visit http:// creativecommons.org/licenses/by-nc-sa/4.0/ 